\title{
Composição química e atividade antibacteriana dos óleos essenciais de cinco espécies de eucalyptus cultivadas em Goiás
}

\author{
Estanislau, A.A. ${ }^{1}$; Barros, F.A.S. ${ }^{1}$; Peña, A.P. ${ }^{2}$; Santos, S.C. ${ }^{3}$; Ferri, P. H. ${ }^{3}$; Paula, J.R.. ${ }^{*}$ \\ ${ }^{1}$ Instituto de Ciências Biológicas; \\ ${ }^{2}$ Estação Florestal Experimental do IBAMA - EFLEX; \\ ${ }^{3}$ Instituto de Química; \\ ${ }^{4}$ Faculdade de Farmácia; \\ Universidade Federal de Goiás
}

\begin{abstract}
RESUMO: Neste trabalho foi realizado um estudo da composição química e da atividade antibacteriana dos óleos essenciais extraídos por hidrodestilação, em aparelho de Clevenger modificado, das folhas dessecadas e trituradas de Eucalyptus cloeziana F. Mueller, E. citriodora Hook, E. saligna Smith, E. grandis Hill ex Maiden, E. microcorys F. Mueller. A análise da composição química foi realizada por CG/EM e a atividade antibacteriana foi avaliada por difusão em ágar contra os microrganismos Escherichia coli 0:158, E. coli ATCC 8739, Staphylococcus aureus ATCC 6538 e Salmonella choleraeseus ATCC 10708. Os óleos essenciais de E. citriodora e E. grandis apresentaram maior efeito inibitório contra bactérias Gram negativas.
\end{abstract}

Unitermos: Eucalyptus spp; óleos essenciais; atividade antibacteriana.

ABSTRACT: Chemical and biological investigation of Eucalyptus cloeziana, E. citriodora, E. saligna, $E$. grandis and $E$. microcorys essential oils were evaluated. The essential oils analysis were performed by GC/MS and the antibacterial activity was assayed in vitro by using the agar diffusion method against Escherichia coli O:158, E. coli ATCC 8739, Staphylococcus aureus ATCC 6538 and Salmonella choleraeseus ATCC 10708. The essential oils of E. citriodora and E. grandis showed a major inhibitory activity against Gran negative bacteria.

Keywords: Eucalyptus species; essential oils; antibacterial activity.

\section{INTRODUÇÃO}

Em diversas partes do mundo, várias espécies de Eucalyptus vêm sendo cultivados e explorados em grande escala há muitos anos. No Brasil, ele é encontrado em todas as regiões, sendo conhecidas cerca de 400 espécies, das quais são utilizadas desde o caule, de onde se extrai a celulose para a indústria do papel, até as folhas, de onde são retirados os óleos essenciais de diferentes composições químicas. 
O eucalipto tem sido considerado útil em várias áreas tais como: ambiental, econômica, medicinal e farmacêutica. O gênero Eucalyptus apresenta as seguintes propriedades terapêuticas: antifúngica, antisséptica, adstringente, antiinflamatória, antibacteriana, cicatrizante e é um desinfetante de grande potencialidade. (GRA et al., 1990; ALVES, 1992; CUÉ et al., 1993; RODRIGUEZ, 1994; MATOS, 1997; SIMÕES et al., 1999).

As infecções bacterianas estão disseminadas pelo mundo, principalmente nos países subdesenvolvidos e, por isso os estudos sobre a atividade antimicrobiana de plantas representam um grande desafio para a descoberta e a identificação de novos fármacos.

Este trabalho teve por objetivo avaliar a atividade antimicrobiana e analisar a composição química dos óleos essenciais das folhas de algumas espécies de Eucalyptus, cultivadas na Estação Florestal Experimental do IBAMA - EFLEX, localizada em Silvânia, Goiás.

\section{MATERIAIS E MÉTODOS}

\section{Material Botânico}

As folhas de Eucalyptus cloeziana F. Mueller, E. citriodora Hook, E. saligna Smith, E. grandis Hill ex Maiden e E. microcorys F. Mueller foram coletadas na Estação Florestal Experimental do IBAMA- EFLEX de Silvânia, em junho de 2000 e dessecadas à temperatura ambiente.

\section{Extração}

Os óleos essenciais das folhas dessecadas e moídas das diferentes espécies de Eucalyptus foram extraídos por hidrodestilação em aparelho de Clevenger modificado por 4 a 5 horas. Os óleos essenciais obtidos foram acondicionados em frascos de vidro e armazenados na temperatura de $-10^{\circ} \mathrm{C}$ até serem usados.

\section{Avaliação da composição química}

As amostras dos óleos essenciais obtidos foram analisadas por cromatografia gasosa, acoplada a espectrometria de massas (CG/EM), no aparelho Shimadzu QP5050A, utilizando uma

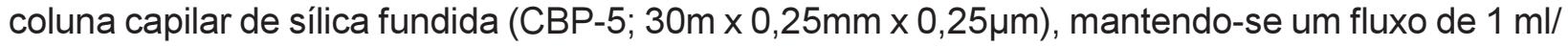
min de Hélio, como gás de arraste, e aquecimento com temperatura programada $\left(60^{\circ} \mathrm{C} / 2 \mathrm{~min}\right.$; $3^{\circ} \mathrm{C} \mathrm{min}^{-1} / 240^{\circ} \mathrm{C} ; 10^{\circ} \mathrm{C} \mathrm{min}^{-1} / 280^{\circ} \mathrm{C} ; 280^{\circ} \mathrm{C} / 10 \mathrm{~min}$ ), e energia de ionização de $70 \mathrm{eV}$. Volume de injeção de $1 \mathrm{ml}$ das amostras diluídas em $\mathrm{CH}_{2} \mathrm{Cl}_{2}$ no modo Split com uma razão de 1:5. A identificação dos componentes dos óleos essenciais foi realizada por comparação dos espectros de massas e índices de retenção com os valores de literatura dos componentes mais comuns de óleos essenciais (ADAMS, 1995). Os índices de retenção foram calculados através da coinjeção de uma mistura de hidrocarbonetos, C 9 - C 22, e com aplicação da equação de Van Den Dool e Kratz (DOOL e KRATZ, 1963; FERRACINI, 1995).

\section{Avaliação da atividade antibacteriana}

\section{Microrganismos utilizados}

Foram utilizadas as seguintes cepas de bactérias: Escherichia coli enteropatogênica clássica monovalente 0:158, isolada de fezes diarréicas de crianças no IPTSP/UFG; Escherichia coli ATCC 8739; Staphylococcus aureus ATCC 6538 e Salmonella choleraeseus ATCC 10708. 
As culturas bacterianas foram repicadas mensalmente e conservadas em geladeira. $\mathrm{A}$ padronização do inóculo empregado nos experimentos foi feita da seguinte maneira: as culturas foram ativadas em Caldo Casoy por $15 \mathrm{~h}$ a $37^{\circ} \mathrm{C}$, obtendo-se assim $10^{8}$ células $/ \mathrm{mL}$, estimadas por comparação ao tubo 0,5 da Escala de Mc Farland, e estas foram inoculadas em meios de cultura para avaliação da atividade antibacteriana.

\section{Avaliação da atividade antimicrobiana por difusão em ágar}

Os microrganismos foram ativados em Caldo Casoy por $15 \mathrm{~h}$ a $37^{\circ} \mathrm{C}$ e inoculados diretamente em placas de Petri contendo Ágar de Mueller Hinton, nas quais foram colocados discos de papéis de $6 \mathrm{~mm}$ de diâmetro (Discos Blank estéreis/ CECON) impregnados com $5 \mu \mathrm{l}$ de cada óleo essencial em estudo. Um controle positivo foi realizado com discos impregnados com $30 \mathrm{mcg}$ de loranfenicol (Sensibiodisc/ CECON). Após a montagem do experimento, as culturas foram incubadas a $37^{\circ} \mathrm{C}$ por $24 \mathrm{~h}$. Os resultados foram obtidos através da observação da presença de halos de inibição e medição de seus diâmetros em milímetros (KONEMAN et al., 1997; IROBI et al., 1994).

\section{RESULTADOS}

\section{Avaliação da atividade antibacteriana}

A Tabela 1 apresenta os valores dos halos de inibição $(\mathrm{mm})$ observados para as amostras dos óleos essenciais extraídos das diferentes espécies de Eucalyptus frente aos microrganismos Escherichia coli enteropatogênica clássica monovalente 0:158, Escherichia coli ATCC 8739, Staphylococcus aureus ATCC 6538 e Salmonella choleraeseus ATCC 10708. Discos impregnados com $30 \mathrm{mcg}$ de cloranfenicol (Sensibiodisc/ CECON) foram utilizados como controle positivo.

Tabela 1. Atividade antibacteriana dos óleos essenciais de várias espécies de Eucalyptus frente a diferentes microrganismos.

\begin{tabular}{l|c|c|c|c}
\hline AMOSTRAS & $\begin{array}{c}\text { Staphylococcus } \\
\text { aureus } \\
\text { ATCC 6538 }\end{array}$ & $\begin{array}{c}\text { Escherichia coli } \\
\text { ATCC 8739 }\end{array}$ & $\begin{array}{c}\text { Escherichia coli } \\
0: 158\end{array}$ & $\begin{array}{c}\text { Salmonella } \\
\text { choleraeseus } \\
\text { ATCC 10708 }\end{array}$ \\
\hline E. cloeziana & 20 & 20 & $(-)$ & $(-)$ \\
\hline E. citriodora & 10 & 10 & 14 & 10 \\
\hline E. grandis & 20 & 10 & 10 & 10 \\
\hline E. microcorys & 08 & $(-)$ & $(-)$ & $(-)$ \\
\hline E. saligna & 14 & 15 & 15 & 15 \\
\hline Cloranfenicol & 25 & 25 & 25 & 25 \\
\hline
\end{tabular}

Os resultados representam o diâmetro do halo de inibição em milímetros; (-) Não houve inibição de crescimento. 


\section{Composição química dos óleos essenciais}

A Tabela 2 apresenta os resultados da análise da composição química, feita por CG/EM, dos óleos essenciais obtidos por hidrodestilação, em aparelho de Clevenger modificado, das folhas das cinco espécies estudadas de eucalipto, bem como os rendimentos dos processos de extração.

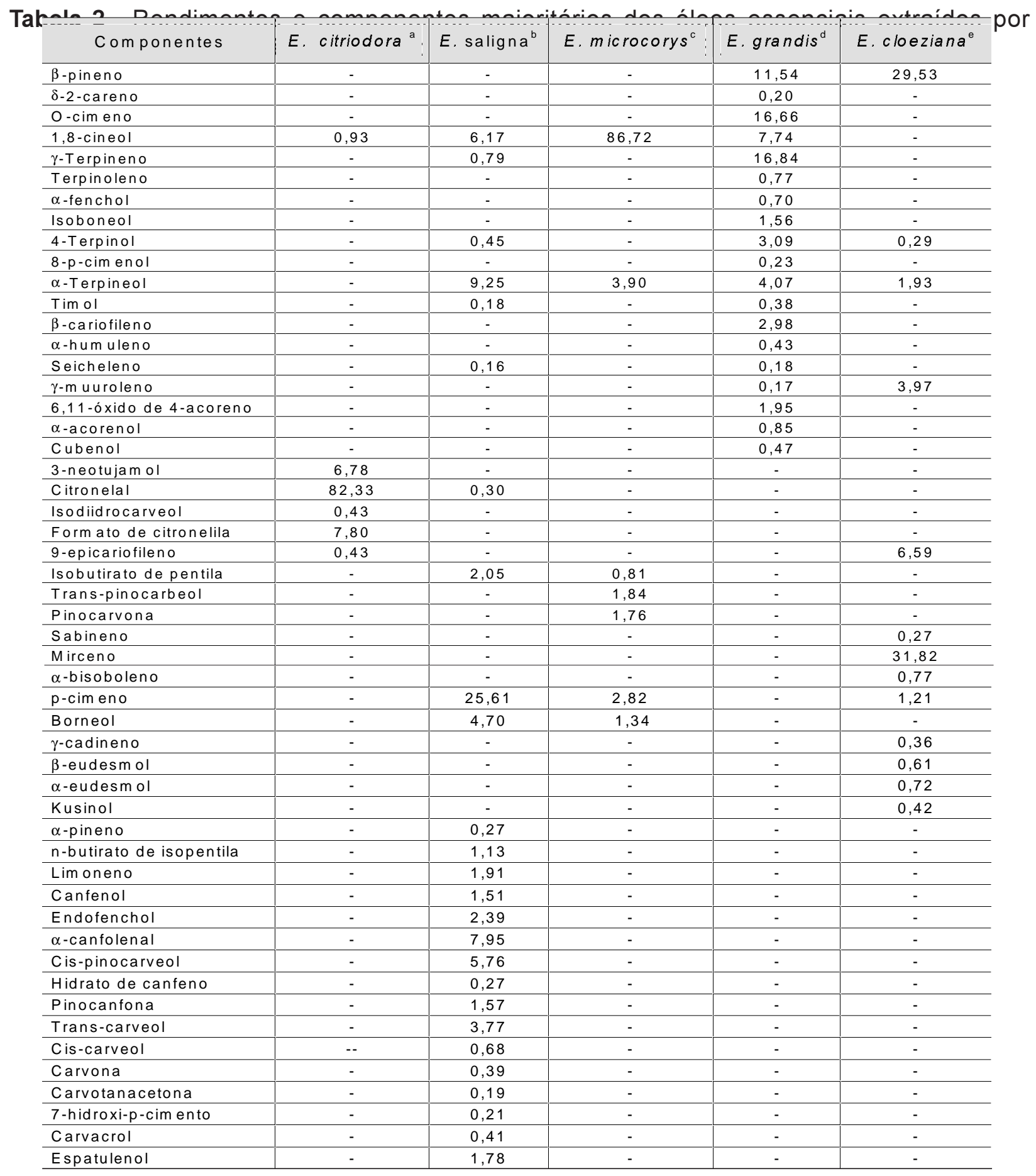

Rendimentos: ${ }^{\mathrm{a}} 4,0 \% ;{ }^{\mathrm{b}} 0,5 \% ;{ }^{\mathrm{c}} 2,5 \% ;{ }^{\mathrm{d}} 2,0 \%$; ${ }^{\mathrm{e}} 0,75 \%$. 


\section{DISCUSSÃO}

Através da avaliação da atividade antibacteriana, observou-se que todos os óleos essenciais testados foram ativos contra Staphylococcus aureus ATCC 6538. O óleo essencial de E. mycrocorys foi o único que não apresentou atividade inibitória sobre E. coli ATCC 8739. Todos os outros exerceram considerável atividade sobre este microrganismo.

Com respeito a E. coli 0:158 foi observado que os óleos essenciais do E. gloeziania e $E$. mycrocorys não apresentaram atividade sobre esse microrganismo. Os óleos de E. cytriodora, E. grandis e E. saligna exerceram atividade inibitória.

Os óleos essenciais de E. gloeziania e E. mycrocorys não apresentaram atividade antimicrobiana para S. choleraeseus ATCC 10708. Os óleos essenciais de E. cytriodora, E. grandis e E. saligna apresentaram resultados satisfatórios de inibição desse microrganismo.

$\mathrm{Na}$ análise da composição química observou-se um predomínio de monoterpenos em todos os óleos essenciais analisados. Foi observado, também, um alto teor de citronelal $(82,33 \%)$ no óleo essencial de E. citriodora. Por ser esta, uma substância irritante da mucosa do trato respiratório, preparações feitas com esta planta não devem ser utilizadas em inalações, corroborando as informações de Matos (1997).

Foi observado um alto teor de 1,8-cineol (86,72\%) no óleo essencial de E. mycrocorys, o que indica que essa espécie pode ser uma importante fonte desta substância, responsável pelas propriedades expectorantes e antissépticas das vias respiratórias de E. globulus Labill. Essa última espécie é de difícil cultivo em regiões de clima quente, como é o caso do Estado de Goiás.

\section{AGRADECIMENTOS}

Ao CNPq, PADCT III/MCT/CNPq e à Fundação de Apoio à Pesquisa-FUNAPE/UFG pelo apoio financeiro.

\section{REFERÊNCIAS BIBLIOGRÁFICAS}

ADAMS, R. P. Identification of essential oil components by gas chromatography/mass spectroscopy. Carol Stream: Allured Publishing Corporation, 1995.

ALVES, A. T. L. S. A utilização da solução natural de eucalipto nas nebulizações, como auxiliar nos tratamentos das infecções respiratórias agudas. Revista Brasileira de Enfermagem, v. 45, n. 2/3, p. 183-186, 1992.

CUÉ, M. T.; RIOS, C. N.; DIAZ, M. E. G.; JIMÉNEZ, J. S. Uso de la tintura de eucalipto en estomatologia. Medicentro, v. 9, n. 2, p. $90-92,1993$.

FERRACINI, V. L. Óleos essenciais de Baccharis e sua interação com insetos polinizadores. Campinas, 1995. 205p. Tese de Doutorado - Instituto de Química, Universidade Estadual de Campinas.

GRA, G.; MAGRANER, J.; ROSADO, A.; BALUJA, R. Analisis del aceite asencial del Eucalyptus grandis (Hill ex Maiden). Revista Cubana de Farmacia, v. 24, n. 1, p. 99 -108, 1990.

IROBI, O. N.; MOO-YOUNG, M.; ANDERSON, W. A.; DARAMOLA, S. O. Antimicrobial activity of bark extracts of Bridella ferruginea (Euphorbiaceae). Journal of Ethnopharmacology, v. 43, n.3, p. 185-190, 1994. 
KONEMAN, E.; ALLEN, S. D.; JAND, W. M.; SCHERECKENBERGER, P. C.; WIN, Jr. W. C. Color atlas and textbook of diagnostic microbiology. 5. ed. Philadelphia: Lippincott, 1997.

MATOS, F. J. A. As plantas das farmácias vivas. Fortaleza: BNB, 1997.

RODRIGUEZ, M. G. Q. Accion antibacteriana del extracto fluido de Eucalyptus citriodora Hook. Estudio in vitro. Revista Cubana de Medicina Militar, v. 23, n. 1, p.3 - 6, 1994.

SIMÕES, C. M. O.; SCHENKEL, E. P.; GOSMANN, G.; MELLO, J. C. P.; MENTZ, L. A.; PETROVICK, P. R. (Org.) Farmacognosia: da planta ao medicamento. Porto Alegre/Florianópolis: UFRGS / EDUFSC, 1999.

DOOL, H. V. D.; KRATZ, P. D. J. A. Generalization of the retention index system including linear temperature programmed gas-liquid partition chromatography. Journal of Chromatography, n. 11, p. 463-471, 1963.

*Autor para correspondência:

Prof. José Realino de Paula Laboratório de Farmacognosia Faculdade de Farmácia Universidade Federal de Goiás Caixa Postal 131

74605-220 - Goiânia - GO

E-mail: jrealino@farmacia.ufg.br 